Andrews University

Digital Commons @ Andrews University

$1-1-2008$

\title{
State Policies Matter: The Case of Outpatient Drug Treatment Program Practices
}

\author{
Jamie Chriqui \\ University of Illinois at Chicago \\ Yvonne Terry-McElrath \\ University of Michigan - Ann Arbor \\ Duane C. McBride \\ Andrews University, mcbride@andrews.edu \\ D Eidson \\ University of Michigan - Ann Arbor
}

Follow this and additional works at: https://digitalcommons.andrews.edu/behavioral-pubs

Part of the Public Health Commons, Social and Behavioral Sciences Commons, and the Substance Abuse and Addiction Commons

\section{Recommended Citation}

Chriqui, Jamie; Terry-McElrath, Yvonne; McBride, Duane C.; and Eidson, D, "State Policies Matter: The Case of Outpatient Drug Treatment Program Practices" (2008). Faculty Publications. 7.

https://digitalcommons.andrews.edu/behavioral-pubs/7

This Article is brought to you for free and open access by the Behavioral Sciences at Digital Commons @ Andrews University. It has been accepted for inclusion in Faculty Publications by an authorized administrator of Digital Commons @ Andrews University. For more information, please contact repository@andrews.edu. 


\title{
Regular article
}

\section{State policies matter: The case of outpatient drug treatment program practices}

\author{
Jamie F. Chriqui, (Ph.D., M.H.S.) ${ }^{\mathrm{a}, \mathrm{b}, *}$, Yvonne Terry-McElrath, (M.H.S.A.) ${ }^{\mathrm{c}}$, \\ Duane C. McBride, (Ph.D.) ${ }^{\mathrm{d}}$, Shelby S. Eidson, (J.D. $)^{\mathrm{b}}$ \\ anstitute for Health Research and Policy, University of Illinois at Chicago, Chicago, IL 60608, USA \\ ${ }^{\mathrm{b}}$ Center for Health Policy and Legislative Analysis, The MayaTech Corporation, Silver Spring, MD 20910, USA \\ ${ }^{\mathrm{c}}$ Institute for Social Research, University of Michigan, Ann Arbor, MI 48104, USA \\ ${ }^{\mathrm{d}}$ Institute for the Prevention of Addictions, Andrews University, Berrien Springs, MI 49104, USA
}

Received 30 May 2007; received in revised form 2 July 2007; accepted 8 August 2007

\begin{abstract}
This study examined relationships between state policy requirements governing outpatient substance abuse treatment services and reported outpatient treatment program practices. State policies effective as of February 1, 2003, and February 1, 2004, were collected and analyzed via primary legal research; data were validated by state officials $(88 \%$ response rate; $>90 \%$ validation rate). Treatment practice data were obtained from the National Survey of Substance Abuse Treatment Services for the years 2003 and 2004. Multivariate analyses clustered by state were conducted, controlling for state, program, and state-aggregated client admission characteristics. Results indicated that treatment programs located in states with requirements for comprehensive substance abuse assessment, family counseling, substance abuse and infectious disease/sexually transmitted disease testing services, HIV/AIDS education, and aftercare services had significantly higher odds of offering such services $(p$ values ranging from $<.05$ to $<.001)$. This study presents new information regarding the potential role that state policy context may play in understanding treatment program practices. (C) 2008 Elsevier Inc. All rights reserved.
\end{abstract}

Keywords: Substance abuse treatment; State policy; Treatment practices; Treatment services; State regulation

\section{Introduction}

Recently, many diverse groups have called for, and have recognized, the role that state legislatures and state executive branch agencies can play in ensuring access to, substance abuse treatment programs that include proven or effective practices. These groups have included major federal and quasi-governmental organizations such as the National Institute on Drug Abuse and the Institute of Medicine,

The views expressed in this article are solely attributable to the authors and do not reflect the views of the Robert Wood Johnson Foundation or its trustees, the University of Illinois at Chicago, or the authors' employers.

* Corresponding author. University of Illinois at Chicago, M/C 275, Room 558, Chicago, IL 60608, USA. Tel.: +1 312996 6410; fax: +1 312 3552801.

E-mail address: jchriqui@uic.edu (J.F. Chriqui). national organizations such as the Robert Wood Johnson Foundation, and panels of experts in the addiction treatment and drug abuse health services research fields (e.g., the Join Together Blueprint for the States Policy Panel) (Blue Ribbon Task Force on Health Services Research, 2004; Committee on Crossing the Quality Chasm: Adaptation to Mental Health and Addictive Disorders, Institute of Medicine, 2006; Robert Wood Johnson Foundation, 2006; Rosenbloom, Garson, Shah, \& Ambrogi, 2006). The relatively recent emphasis on states' roles in ensuring the provision of proven and effective practices in substance abuse treatment settings stems from several key factors. First, although federal, state, and local governments are the primary payers of substance abuse treatment services in the United States, the majority of substance abuse treatment services in the United States are paid for by state governments (Mark et al., 2005); thus, states have a vested interest in seeing that clients receive quality 
treatment services. Second, with the exception of federal regulations for certifying opioid treatment programs, state governments are primarily responsible for authorizing substance abuse treatment programs in the United States (Chriqui, Terry-McElrath, McBride, Eidson, \& VanderWaal, 2007). Consequently, substance abuse treatment programs are governed by a diverse set of state policies. The adoption and diffusion of evidence-based practices are largely left to treatment program organization and provider decisions. Third, concerns have been raised regarding the provision of quality care in substance abuse treatment settings. McGlynn et al. (2003) published in the New England Journal of Medicine a seminal study documenting adherence to quality-of-care indicators for 30 acute and chronic conditions, including alcohol dependence. Their study concluded that alcohol dependence ranked lowest in terms of the percentage of recommended quality care received (only 10.5\%; McGlynn et al., 2003).

To date, the substance abuse treatment literature has documented the role of organizational and management factors in substance abuse treatment delivery (for a review of the key literature and findings in this area, see, e.g., D'Aunno, 2006). Program ownership, organizational affiliation, client:staff ratios, Joint Commission on the Accreditation of Healthcare Organizations accreditation, managed care relationships, clinical supervisors' graduate medical education, and managerial practices are among the factors contributing to program incorporation of established or proven practices (Alexander, Nahra, \& Wheeler, 2003; D’Aunno, 2006; D'Aunno \& Vaughn, 1995; Friedmann, Alexander, \& D'Aunno, 1999; Wells, Lemak, \& D'Aunno, 2006). Yet, as D'Aunno has recently concluded, many of the factors affecting treatment program organization and management are structural in nature and may require "large-scale policy changes to improve treatment practices and outcomes" (D'Aunno, 2006).

At the same time, research has shown that a comprehensive approach to substance abuse treatment is considered ideal (National Institute on Drug Abuse, 1999). Such an approach includes comprehensive intake/assessment (American Psychiatric Association, 1994; McLellan, Luborsky, Woody, \& O'Brien, 1980; Mee-Lee, Shulman, Fishman, Gastfriend, \& Griffith, 2005; Morgan, Morgenstern, Blanchard, Labouvie, \& Bux, 2003; Thom et al., 1992); behavioral therapies including counseling services (Avants, Margolin, Usubiaga, \& Doebrick, 2004; McLellan, Arndt, Metzger, Woody, \& O'Brien, 1993); infectious disease/sexually transmitted disease (STD) testing and education services (Batki \& Ferrando, 1996; Broome, Joe, \& Simpson, 1999); transitional assistance and ancillary services (Lo, MacGovern, \& Bradford, 2002; McCarty, 2000; Orwin, Ellis, Williams, \& Maranda, 2000; Reif, Horgan, Ritter, \& Tompkins, 2004); and relapseprevention (Annis, 1991; Carroll, 1996; Irvin, Bowers, Dunn, \& Wang, 1999; Witkiewitz \& Marlatt, 2004) and continuing care/aftercare services (Brown, Seraganian, Tremblay, \& Annis, 2002; Siegal, Li, \& Rapp, 2002). Interestingly, the substance abuse treatment, health services research, and public health policy fields have failed to thoroughly document the nature and extent of state policy requirements for the provision of these services by treatment programs that are state authorized. Furthermore, researchers have yet to examine the relationship between state policy requirements and actual treatment program practices. Understanding the nature of this relationship, if any, is important because, without a national regulatory system, state policy requirements are one of the only common denominators (aside from federal block grant requirements and voluntary national accrediting body requirements) that could help to effectuate the use, incorporation, or use and incorporation of proven and effective practices into state-authorized treatment programs (i.e., the vast majority of programs operating today). Furthermore, without an understanding of this relationship, a potentially important contextual component of the substance abuse treatment delivery system may be overlooked. This study aims to begin to fill this gap by examining whether state policy requirements do, indeed, relate to actual treatment program practices.

\section{Materials and methods}

\subsection{Data sources}

\subsubsection{Independent variables: State policy data}

State policy requirements governing state-authorized standard outpatient substance abuse treatment programs (for further discussion of the state authorization process and its relationship to outpatient treatment program practices, see Chriqui et al., 2007) were captured using primary legal research methods (Mersky \& Dunn, 2002). For purposes of this research, "state" was defined to include each of the 50 states and the District of Columbia. State statutory and regulatory policies (hereafter referred to as "state policies") effective as of February 1, 2003, and February 1, 2004, were obtained via searches of relevant Westlaw state policy databases. Westlaw is a commercial service provider of electronic legal reference information. To ensure comprehensive capture of potentially relevant state policies, Boolean text-based searches of the Westlaw state policy databases were combined with detailed reviews of statutory tables of content and indices available from Westlaw. Tables of content and indices were not available for state regulatory laws for the reference dates of interest.

Dichotomous coding schemes were used to capture state requirements for the provision of 16 evidenced-based services (National Institute on Drug Abuse, 1999) spanning five treatment service areas provided by outpatient programs seeking state authorization: (1) recognition of treatment need, (2) counseling services, (3) testing services, (4) HIV/ AIDS education services, and (5) maintenance of treatment effects (including relapse-prevention and continuing care/ aftercare services). The "recognition of treatment need" 
Table 1

Study sample descriptive statistics

\begin{tabular}{|c|c|c|c|c|}
\hline N-SSATS treatment program outcomes & No. & $\%$ & State policies for standard outpatient requirement predictors $(n=9,025)$ & $\%$ \\
\hline \multicolumn{5}{|l|}{ Recognition of treatment need } \\
\hline $\begin{array}{l}\text { 1. Comprehensive substance abuse } \\
\text { assessment/diagnostic services provided }\end{array}$ & 9,017 & 97.4 & 1. Comprehensive substance abuse assessment requirement & 95.7 \\
\hline 2. Patient placement, diagnostic criteria, or both & & & 2. Patient placement, diagnostic criteria, or both & \\
\hline \multirow[t]{3}{*}{ Not captured in N-SSATS } & & & Use of ASAM patient placement criteria & 20.3 \\
\hline & & & Use of $D S M-I V$ diagnostic criteria & 27.4 \\
\hline & & & Use of ASI diagnostic criteria & 7.2 \\
\hline \multicolumn{5}{|l|}{ Treatment provision } \\
\hline 1. Counseling services provided & & & 1. Counseling services required & \\
\hline Family counseling & 8,947 & 76.8 & Family counseling/therapy & 39.6 \\
\hline Group therapy & 8,994 & 94.3 & Group counseling/therapy & 87.4 \\
\hline Individual therapy & 8,989 & 96.4 & Individual counseling/therapy & 85.3 \\
\hline 2. Testing services provided & & & 2. Testing services required & \\
\hline Drug or alcohol urine screening & 9,004 & 86.1 & Drug or alcohol testing/screening & 5.5 \\
\hline Screening for hepatitis B & 8,865 & 17.5 & Hepatitis B or C testing/screening & 9.4 \\
\hline Screening for hepatitis $\mathrm{C}$ & 8,870 & 18.1 & & \\
\hline HIV testing & 8,903 & 29.2 & HIV/AIDS testing & 12.6 \\
\hline STD testing & 8,860 & 17.9 & STD testing & 10.8 \\
\hline TB screening & 8,890 & 30.5 & TB testing & 11.5 \\
\hline 3. Education services provided & & & 3. Education services required & \\
\hline HIV or AIDS education, counseling, or support & 8,985 & 57.3 & HIV/AIDS education & 35.6 \\
\hline \multicolumn{5}{|l|}{ Maintenance of treatment effects } \\
\hline 1. Relapse prevention & 8,948 & 86.7 & 1. Relapse prevention & 28.0 \\
\hline 2. Aftercare counseling & 8,973 & 86.7 & 2. Continuing care/aftercare counseling & 42.8 \\
\hline
\end{tabular}

category includes requirements for comprehensive assessment as well as requirements for three measures of patient placement, diagnostic criteria or both for use of: (1) American Society for Addiction Medicine (ASAM) patient placement criteria for outpatient and intensive outpatient substance abuse treatment (ASAM Levels I and II.1; MeeLee et al., 2005); (2) the Diagnostic and Statistical Manual of Mental Disorders, Fourth Edition (DSM-IV), which contains criteria for diagnosing both substance abuse and dependence (American Psychiatric Association, 1994); and (3) the Addiction Severity Index (ASI), a comprehensive addictions assessment and monitoring tool that can be used to evaluate substance use, as well as medical, employment, legal, family, social, and psychiatric status (McLellan et al., 1980, 1992). The "counseling services" category includes requirements for the provision of family, group, and individual counseling services. The "testing services" category includes requirements for substance use, HIV/ AIDS, tuberculosis (TB), STDs, and hepatitis B or C testing. The "maintenance of treatment effects" category includes requirements for the provision of relapse-prevention and continuing care/aftercare services. Table 1 (column 2) provides a detailed listing of state policy variables.

Following identification and coding of state policy requirements, state authorizing officials were contacted via an electronic mail survey to confirm accurate coding of the state's data. Responses were received from 45 states $(88 \%$ response rate) and revealed that our initial coding was correct in $>90 \%$ of the cases. In the remaining cases, the data were corrected to reflect the state's response.
Data for 47 states were included in the analysis. Alaska and South Dakota were excluded because programs in these states were not required to be authorized as of the study reference dates; the state authorization process was voluntary. Hawaii was excluded because its accreditation requirements had not yet been promulgated (i.e., they were in draft format) as of the study reference dates. The District of Columbia was excluded due to missing data for one of the study years.

\subsubsection{Outcome variables: National Survey of Substance Abuse Treatment Services program data}

Outpatient substance abuse treatment program practice data for 2003 and 2004 were obtained from the Substance Abuse and Mental Health Services Administration's (SAMHSA) National Survey of Substance Abuse Treatment Services (N-SSATS; U.S. Department of Health and Human Services, 2005). N-SSATS is an annual point-prevalence survey of the location, characteristics, services, and number of clients enrolled in treatment at public and private treatment facilities in the United States. The N-SSATS reference date is March 31 of each year. Although not considered a census of substance abuse treatment programs in the United States, N-SSATS has been determined to provide a satisfactory national sampling frame for substance abuse treatment services, having accurately identified $70 \%$ of all substance abuse facilities in a midsize city (Carise, McLellan, Festinger, \& Kleber, 2005).

Data from 10,877 publicly funded standard and intensive outpatient treatment programs were obtained from the 
N-SSATS data for the 47 states noted above. Programs that did not report substance abuse treatment as their primary focus (i.e., mental health, combined mental health and substance abuse treatment, and health care), as well as tribally and federally owned treatment programs, were excluded. We only selected publicly funded outpatient treatment programs included in N-SSATS because state policy requirements generally are mandated for programs receiving state authorization (which includes all programs receiving state funding). Outpatient programs were selected for analysis because, as the 2004 full N-SSATS data show, the vast majority of treatment programs in the United States offer standard outpatient (72\%) or intensive outpatient (42\%) services as compared to residential $(27 \%)$, day treatment $(14 \%)$, detoxification (21\%), methadone/ $\mathrm{L}-\alpha$-acetylmethadol maintenance $(7 \%)$, or hospital inpatient $(8 \%)$ services (U.S. Department of Health and Human Services, Substance Abuse and Mental Health Services Administration, Office of Applied Studies [U.S. DHHS, SAMHSA, OAS], 2006a).

All outcome variables were dichotomous and were listed after question stems in the N-SSATS survey instrument, which read, "Which of the following ["substance abuse services" or "services"] are provided by this facility at this location...?" Thirteen outcomes were selected for analysis (Table 1, column 1), covering the five service areas noted earlier: recognition of treatment need, counseling services, testing services, HIV/AIDS education services, and maintenance of treatment effects.

\subsubsection{Control variables}

A series of control variables were included to account for possible confounding influences of state- and program-level characteristics. State outpatient substance abuse treatment program authorization type (i.e., certification/accreditation vs. licensure) was controlled for because prior research has documented the relationship between authorization type and outpatient treatment program practices (Chriqui et al., 2007). Other state-level control variables included state median household income (U.S. Census Bureau, 2005) and Democratic Party in power for the governor and state legislature (National Conference of State Legislatures, 2000a, 2000b, 2002a, 2002b). Democratic Party status was of interest because self-affiliated Democratic Party voters in the 2004 presidential election were significantly more likely to identify quality of health care as an important issue confronting the nation than were self-reported independent or Republican voters (Blendon, Brodie, Altman, Benson, \& Hamel, 2005). To account for the policy lag effect of the party in power on state policy provisions in effect in 2003 and 2004, political party data from the 2000 and 2002 elections were used (i.e., the 2004 elections occurred following the study reference dates). We were unable to find a suitable indicator of state-level expenditures on substance abuse treatment services. Future analyses would be well served to include expenditure data should they become available.
Four program-level controls were obtained from N-SSATS: (1) program ownership type, (2) program-reported state authorization agency type, (3) client counts, and (4) payment assistance acceptance. Program ownership type has been well documented to relate to treatment program practices and service offerings (D'Aunno, 2006; Knudsen, Ducharme, \& Roman, 2006; Roman, Ducharme, \& Knudsen, 2006; Wells, Lemak, \& D'Aunno, 2005; Wheeler, Fadel, \& D'Aunno, 1992). Program-reported state authorization agency data were included because analyses conducted by the study team indicated that treatment program practices vary according to the type of state agency (i.e., substance abuse, public health, and mental health) responsible for authorizing the program. The final two program-level controls included a quartile client count measure (defined as the total number of clients in standard or intensive outpatient treatment; quartile definition was based on data for all 50 states plus the District of Columbia) and a dichotomous variable indicating whether the program offered payment assistance.

Three aggregated state-level client characteristics variables were obtained from SAMHSA's Treatment Episode Data Set for the 2003 and 2004 periods because client characteristics data were not available in the N-SSATS data set: percent employed, percent male, and percent outpatient (U.S. Department of Health and Human Services, Substance Abuse and Mental Health Services Administration, Office of Applied Studies (U.S. DHHS, SAMHSA, OAS), 2006b, 2006c). Furthermore, a year 2004 dummy variable was included to control for time trends.

\subsection{Data analysis}

Analyses were conducted using Stata v.9.2, using the logistic command and clustering by state. State clustering was utilized to account for the lack of independence between programs within the same state having the same values for state-level independent and control variables.

\section{Results}

Missing data due to nonresponse were present on some of the N-SSATS variables used as controls. Thus, after deleting cases with missing control data and data for states with voluntary or unpromulgated policy provisions, 9,025 cases remained for analysis ( $83 \%$ of the original 10,877 cases). Table 1 presents descriptive statistics for all outcome and predictor variables.

\subsection{State policy requirements}

Virtually all programs (96\%) were in a state with policies requiring mandatory assessment for substance abuse treatment programs. However, specification of particular patient placement, diagnostic criteria, or both 
Table 2

Multivariate analyses of the relationship between state policy requirements and reported treatment program practices

\begin{tabular}{|c|c|c|c|c|c|}
\hline N-SSATS outcome & Policy predictor & $\%$ & Odds ratio & $p$ & $95 \%$ confidence interval \\
\hline \multicolumn{6}{|l|}{ Treatment provision } \\
\hline \multicolumn{6}{|l|}{ 1. Counseling services } \\
\hline \multirow{3}{*}{ Family counseling $(n=8,947)$} & \multicolumn{5}{|c|}{ Family counseling/therapy } \\
\hline & No & 73.6 & (ref) & & \\
\hline & Yes & 81.8 & 1.42 & $* *$ & $1.13,1.77$ \\
\hline \multirow[t]{3}{*}{ Group therapy $(n=8,994)$} & \multicolumn{5}{|c|}{ Group counseling/therapy } \\
\hline & No & 94.2 & (ref) & & \\
\hline & Yes & 94.3 & 1.23 & & $0.81,1.86$ \\
\hline \multirow[t]{3}{*}{ Individual therapy $(n=8,989)$} & \multicolumn{5}{|c|}{ Individual counseling/therapy } \\
\hline & No & 96.5 & (ref) & & \\
\hline & Yes & 96.4 & 0.84 & & $0.37,1.88$ \\
\hline \multicolumn{6}{|l|}{ 2. Testing services } \\
\hline \multirow[t]{3}{*}{ Drug or alcohol urine screening $(n=9,004)$} & \multicolumn{5}{|c|}{ Drug or alcohol screening/testing } \\
\hline & No & 85.7 & (ref) & & \\
\hline & Yes & 93.8 & 7.25 & $* * *$ & $3.47,15.13$ \\
\hline \multirow[t]{3}{*}{ Screening for hepatitis B $(n=8,865)$} & \multicolumn{5}{|c|}{ Hepatitis B or C testing } \\
\hline & No & 17.2 & (ref) & & \\
\hline & Yes & 20.4 & 1.97 & $* *$ & $1.32,2.93$ \\
\hline \multirow[t]{3}{*}{ Screening for hepatitis $\mathrm{C}(n=8,870)$} & \multicolumn{5}{|c|}{ Hepatitis B or C testing } \\
\hline & No & 17.6 & (ref) & & \\
\hline & Yes & 22.5 & 2.25 & $* * *$ & $1.45,3.48$ \\
\hline \multirow[t]{3}{*}{ HIV testing $(n=8,903)$} & HIV/AIDS testin & & & & \\
\hline & No & 27.4 & (ref) & & \\
\hline & Yes & 41.3 & 4.01 & $* * *$ & $2.50,6.45$ \\
\hline \multirow[t]{3}{*}{ STD testing $(n=8,860)$} & STD testing & & & & \\
\hline & No & 16.8 & (ref) & & \\
\hline & Yes & 26.6 & 2.37 & $* *$ & $1.44,3.90$ \\
\hline \multirow[t]{3}{*}{ TB screening $(n=8,890)$} & TB testing & & & & \\
\hline & No & 29.9 & (ref) & & \\
\hline & Yes & 34.6 & 1.70 & $*$ & $1.13,2.56$ \\
\hline \multicolumn{6}{|l|}{ 3. Education services (any) } \\
\hline \multirow[t]{3}{*}{ HIV/AIDS education/counseling/support $(n=8,985)$} & \multicolumn{5}{|c|}{ HIV/AIDS education } \\
\hline & No & 54.3 & (ref) & & \\
\hline & Yes & 62.7 & 1.62 & $* * *$ & $1.31,2.02$ \\
\hline \multicolumn{6}{|l|}{ Maintenance of treatment effects } \\
\hline \multirow[t]{3}{*}{ 1. Relapse-prevention groups $(n=8,948)$} & \multicolumn{5}{|c|}{ Relapse prevention } \\
\hline & No & 85.3 & (ref) & & \\
\hline & Yes & 90.1 & 1.33 & & $0.83,2.14$ \\
\hline \multirow[t]{3}{*}{ 2. Aftercare counseling $(n=8,973)$} & Continuing care/ & are cour & & & \\
\hline & No & 86.0 & (ref) & & \\
\hline & Yes & 87.6 & 1.59 & $* *$ & $1.13,2.25$ \\
\hline
\end{tabular}

Notes. Only one policy variable was entered per model. ref = referent. Models clustered by state. Models clustered by state and controlled for the following: state licensure/certification and deemed status policy, program-reported authorizing agency, program ownership, governor democratic party, legislature democratic party, state median household income, state treatment client admission characteristics (percent employed, percent male, percent outpatient, client count, and payment assistance), and year 2004 dummy.

$* p<.05$.

$* * p<.01$.

$* * * p<.001$

was less frequent. Only one fifth of programs were in a state that required the use of ASAM Patient Placement Criteria for the Treatment of Substance-Related Disorders, and just more than one quarter required the use of the $D S M-I V$. Very few programs $(7 \%)$ were in a state requiring the use of the ASI. Requirements for group and individual counseling/therapy were widespread $(>85 \%$ of programs were located in states with such requirements); however, only $40 \%$ of programs were located in states with similar requirements for family counseling/therapy. Of interest was the low percentage of programs located in states requiring specific testing services. Only $6 \%$ of programs were in a state actually requiring drug or alcohol testing/screening. State testing requirements for diseases associated with substance use (hepatitis B and C, HIV/AIDS, STDs, and TB) were present for only $9-13 \%$ of programs. Requirements for HIV/AIDS education, however, were more prevalent; more than one third of programs were in states with such policies. Finally, 28\% of programs were in states with requirements regarding relapse-prevention services, 
and nearly half $(43 \%)$ of the programs were located in states with requirements for continuing care/aftercare counseling services.

\subsection{Treatment program practices}

Section 3.1 described the nature and extent of the state level policies. It is the purpose of this paragraph to report the distribution of actual program service practices from the N-SSATS data. Virtually all programs reported providing comprehensive assessment or diagnosis services (97\%), as well as group (94\%) and individual (96\%) therapies. Family counseling was somewhat less prevalent, but was still provided by the strong majority of programs (77\%). Eightysix percent of programs reported performing urine screening for drug or alcohol abuse. However, testing for diseases associated with substance use was much less prevalent. Less than $20 \%$ of programs reported testing for hepatitis B or C or for STDs. Less than one third of programs reported testing for HIV (29\%) or TB (31\%). In contrast, more than half $(57 \%)$ of programs reported providing HIV/AIDS education, counseling, or support. Services aimed at maintaining treatment effects were also widespread; $87 \%$ of programs provided relapse-prevention and continuing care/aftercare counseling.

\subsection{Multivariate relationships between state policy requirements and treatment program practices}

As noted in Materials and Methods, multivariate models controlled for a variety of program- and state-level factors. Results are presented in Table 2.

\subsubsection{Assessment services}

As stated previously, the percentage of outpatient programs reporting the use of comprehensive assessment was very high overall (97\%). Given the lack of variance in this measure, multivariate models examining the odds of comprehensive assessment by state assessment did not provide meaningful results and are not shown in Table 2. Unfortunately, N-SSATS does not capture the program use of ASAM, DSM-IV criteria, or the ASI. Thus, we were unable to assess the direct relationship between state requirements for and treatment program use of these tools.

\subsubsection{Counseling services}

Outpatient programs' use of counseling services was partially associated with state policy requirements in this area. Although state requirements governing group and individual counseling services were not associated with program use of these services (such services were almost universal), programs in states requiring family counseling services had significantly higher odds of reporting the provision of such services (82\%) as compared to programs in states without such requirements (74\%).

\subsubsection{Testing and education services}

Across the board, in each instance where state policy required the use of testing services, outpatient treatment programs had significantly higher odds of conducting the testing services than programs in states without such policy requirements. Similarly, programs in states requiring HIV/ AIDS education/awareness programs had significantly higher odds of providing such services $(63 \%)$ than programs in states without such requirements (54\%).

\subsubsection{Relapse-prevention and aftercare services}

Data indicated that state policy is not associated with the provision of relapse-prevention services (i.e., services offered during treatment designed to prevent the reinitiation of substance use). However, significant associations were observed with the provision of continuing care/aftercare services (i.e., services provided after treatment completion to help ensure the ongoing effect of treatment services). Models showed that programs in states with aftercare requirements had significantly higher odds of providing such services than programs in states without such requirements. Significant results were somewhat surprising, given the minimal difference in the percentage of programs offering aftercare services based only on state requirements for continuing care/aftercare ( $86 \%$ of programs in states without policy vs. $88 \%$ of programs in states with policy). Further investigation showed a significant interaction between program provision of aftercare services and state policy requirements for such services based on state authorization type (i.e., certification/ accreditation vs. licensure). Specifically, programs were more likely to provide aftercare services if the state policy required it and if the program was located in a certification/ accreditation state (as compared to a licensure state).

\section{Discussion}

The findings reported herein provide initial empirical evidence of the potential role that state policy may play in effectuating certain evidence-based outpatient substance abuse treatment program practices. Although we were not able to explore all possible relationships, the data indicate that a relationship does exist between state policy requirements and treatment program practices relative to family counseling, drug and alcohol screening, infectious disease/ STD testing and education services, and aftercare services. Furthermore, in the case of group and individual counseling services, it was not surprising that we did not find a statistically significant difference in the relationship between programs in states with and without requirements for the provision of such services because state requirements and program practices in this area were nearly universal.

The results of this study seem to indicate that state policy requirements governing outpatient substance abuse treatment programs may have significant public health implications. These findings build on prior research that indicated a 
potential relationship between state policy and program practices, namely, that state authorization type (i.e., certification/ accreditation vs. licensure) was significantly associated with the provision of infectious disease testing services (among other services; Chriqui et al., 2007). In this study, we further confirmed that a relationship does appear to exist between state policy requirements and program provision of infectious disease/STD testing and education services. It is clearly the case that the current analyses do not indicate whether state policy preceded services. However, inclusion of policy requirements regarding the provision of infectious disease/STD testing in state policies is a fairly low-cost policy mandate (relative to other mandates) that could have enormous public health benefits because of the documented link between substance use/abuse and infectious disease/ STD (Aktan, Calkins, \& Johnson, 2001; Batki \& Ferrando, 1996; Broome et al., 1999; Edlin et al., 2005; Holmberg, 1996; National Institute on Drug Abuse, 1999; Nyamathi, Sands, Pattatucci-Aragon, Berg, \& Leake, 2004).

The findings reported herein are subject to several limitations. First, cross-sectional analyses, based on only 2 years of data, were presented and, therefore, should not be interpreted to reflect long-term trends in state policy, nor can the results be interpreted causally. Ongoing research is planned by the study team to continually monitor the relationship between state policy requirements and treatment program practices over time to ascertain whether the relationships are maintained. Second, this study was limited to policy requirements and treatment program practices specific to outpatient treatment settings and, therefore, the results should not be generalized to all treatment settings. Third, it is not possible to generalize the relationships reported to all state policy requirement/treatment program practice relationships. Limitations in both the state policy collection and the N-SSATS data sets precluded inclusion of certain variables, including pharmacotherapies, transitional assistance, and ancillary services. Fourth, we were unable to explore the relationship between state policy requirements for use of ASAM Patient Placement Criteria for the Treatment of Substance-Related Disorders, the DSM-IV, and/or the ASI and treatment program practices in this area because N-SSATS does not ask treatment programs to report on their practices in this area. Thus, we were limited to assessing the extent to which programs provide, and the extent to which states mandate the use of, comprehensive assessment at intake. What tools or diagnostic criteria may or may not be employed by the treatment programs based on state requirements for use of these tools are unknown and provide an interesting question for future research. Fifth, although N-SSATS has been reported elsewhere as being a suitable source of treatment service data (Carise et al., 2005), responses to the survey are voluntary and, therefore, subject to response bias, including varying levels of knowledge, expertise, or both on the part of the respondents to the N-SSATS questionnaire. Furthermore, responses to the N-SSATS service variables are often reported in the affirmative even if only one client of a given service provider has received the given service. Thus, N-SSATS treatment program reporting of service provision is not necessarily reflective of a service provided to a majority of clients in the given program and, therefore, analyses involving the N-SSATS data may contain an overestimation of the services actually provided to clients. Finally, as indicated above, we were unable to control for all possible factors that might confound the relationship between state policy requirements and treatment program practices, including state-level treatment program expenditures, geographic location of the treatment programs included in N-SSATS, and actual client characteristics for the treatment programs included in N-SSATS. Future analyses would be well served to control for these and other variables should they become available.

In spite of these limitations, the data reported herein seem to further provide evidence of a relationship between state policy requirements and treatment program practices as reported in N-SSATS. Research has indicated that program practices varied based on the state authorization approach governing outpatient treatment programs (i.e., certification/ accreditation vs. licensure; Chriqui et al., 2007). The current study also points to interesting relationships between state policy requirements and reported outpatient treatment program practices and, in the case of aftercare services, indicates a more complex interaction between program practice, state policy requirement for a service, and state authorization type. Further exploration of these interactions is the subject of future research. However, this study provides additional new data indicating that state policy requirements may, in fact, provide an important context surrounding outpatient substance abuse treatment program practices. Because state policy requirements are mandatory for state-authorized programs (i.e., all programs included in this study), the states are uniquely positioned to institute specific policy proscriptions emanating from scientific research in the substance abuse treatment arena, indicating that a comprehensive approach, specific services, or both are associated with positive treatment outcomes and reduced recidivism (Committee on Crossing the Quality Chasm: Adaptation to Mental Health and Addictive Disorders, Institute of Medicine, 2006; National Institute on Drug Abuse, 1999). Such data may be used to inform future state policy decision-making practices regarding outpatient substance abuse treatment program requirements. These data also imply the importance of a closer working relationship between researchers and clinicians who identify effective treatment practices and state policy makers. It is not sufficient to document and publish in relevant journals what services are effective. It is crucial for health services researchers to work with policy makers to incorporate best treatment practices into state policy and regulations. The data presented suggest that such implementation offers the potential to improve the quality of service received by those in drug treatment programs in that state. 


\section{Acknowledgments}

Work on this article was supported by the ImpacTeen project funded by the Robert Wood Johnson Foundation (Frank J. Chaloupka, University of Illinois at Chicago, Principal Investigator). The authors are especially grateful to Victor Capoccia, Ph.D., for providing initial guidance in conceptualizing this research study. The authors would also like to thank Douglas Ross and Jacque Giem for data collection and research assistance.

\section{References}

Aktan, G. B., Calkins, R. F., \& Johnson, D. R. (2001). Substance use, need, and demand for substance user treatment services in patients treated for sexually transmitted diseases in Michigan. Substance Use \& Misuse, 36, $1651-1676$

Alexander, J. A., Nahra, T. A., \& Wheeler, J. R. (2003). Managed care and access to substance abuse treatment services. Journal of Behavioral Health Services \& Research, 30, 161-175.

American Psychiatric Association. (1994). Diagnostic and statistical manual of mental disorders (4th ed.). Washington, DC: Author.

Annis, H. M. (1991). A cognitive-social learning approach to relapse: Pharmacotherapy and relapse prevention counseling. Alcohol and Alcoholism Supplement, 1, 527-530.

Avants, S. K., Margolin, A., Usubiaga, M. H., \& Doebrick, C. (2004). Targeting HIV-related outcomes with intravenous drug users maintained on methadone: A randomized clinical trial of a harm reduction group therapy. Journal of Substance Abuse Treatment, 26, 67-78.

Batki, S. L., \& Ferrando, S. J. (1996). Diagnosis and treatment of substance use disorders in patients with HIV infection. International Review of Psychiatry, 8, 245-253.

Blendon, R. J., Brodie, M., Altman, D. E., Benson, J. M., \& Hamel, E. C. (2005). Voters and health care in the 2004 election. Health Affairs, Supplement Web Exclusives, W5.

Blue Ribbon Task Force on Health Services Research. (2004). Report of the Blue Ribbon Task Force on Health Services Research at the National Institute on Drug Abuse. Bethesda, MD: U.S. Department of Health and Human Services, National Institutes of Health, National Institute on Drug Abuse.

Broome, K. M., Joe, G. W., \& Simpson, D. D. (1999). HIV risk reduction in outpatient drug abuse treatment: Individual and geographic differences. AIDS Education and Prevention, 11, 293-306.

Brown, T. G., Seraganian, P., Tremblay, J., \& Annis, H. (2002). Process and outcome changes with relapse prevention versus 12-Step aftercare programs for substance abusers. Addiction, 97, 677-689.

Carise, D., McLellan, A. T., Festinger, D. S., \& Kleber, H. D. (2005). Identifying United States substance abuse treatment programs: A test in one mid-sized city. Substance Abuse, 25, 21-28.

Carroll, K. M. (1996). Relapse prevention as a psychosocial treatment: A review of controlled clinical trials. Experimental and Clinical Psychopharmacology, 4, 46-54.

Chriqui, J. F., Terry-McElrath, Y., McBride, D. C., Eidson, S. S., \& VanderWaal, C. J. (2007). Does state certification or licensure influence outpatient substance abuse treatment program practices? Journal of Behavioral Health Services \& Research, 34, 309-328.

Committee on Crossing the Quality Chasm: Adaptation to Mental Health and Addictive Disorders, Institute of Medicine. (2006). Improving the quality of health care for mental health and substance-use conditions. Washington, DC: National Academy Press.

D'Aunno, T. (2006). The role of organization and management in substance abuse treatment: Review and roadmap. Journal of Substance Abuse Treatment, 31, 221-233.
D’Aunno, T., \& Vaughn, T. E. (1995). An organizational analysis of service patterns in outpatient drug abuse treatment units. Journal of Substance Abuse, 7, 27-42.

Edlin, B. R., Kresina, T. F., Raymond, D. B., Carden, M. R., Gourevitch, M. N., Rich, J. D., et al. (2005). Overcoming barriers to prevention, care, and treatment of hepatitis $\mathrm{C}$ in illicit drug users. Clinical Infectious Diseases, 40(Suppl 5), S276-S285.

Friedmann, P. D., Alexander, J. A., \& D’Aunno, T. A. (1999). Organizational correlates of access to primary care and mental health services in drug abuse treatment units. Journal of Substance Abuse Treatment, 16, $71-80$

Holmberg, S. D. (1996). The estimated prevalence and incidence of HIV in 96 large U.S. metropolitan areas. American Journal of Public Health, $86,642-654$

Irvin, J. E., Bowers, C. A., Dunn, M. E., \& Wang, M. C. (1999). Efficacy of relapse prevention: A meta-analytic review. Journal of Consulting and Clinical Psychology, 67, 563-570.

Knudsen, H. K., Ducharme, L. J., \& Roman, P. M. (2006). Early adoption of buprenorphine in substance abuse treatment centers: Data from the private and public sectors. Journal of Substance Abuse Treatment, 30, 363-373.

Lo, W., MacGovern, T., \& Bradford, J. (2002). Association of ancillary services with primary care utilization and retention for patients with HIV/AIDS. AIDS Care, 14, S45-S57.

Mark, T., Coffey, R. M., McKusick, D., Harwood, H., King, E., Bouchery, E., et al. (2005). National estimates of expenditures for mental health services and substance abuse treatment, 1991-2001 (SAMHSA Publication No. SMA 05-3999). Rockville, MD: Substance Abuse and Mental Health Services Administration.

McCarty, D. (2000). Between despair and hope: Health services research on treatment of alcohol abuse. Addiction, 95(Suppl 3), S439-S447.

McGlynn, E. A., Asch, S. M., Adams, J., Keesey, J., Hicks, J., DeCristofaro, A., et al. (2003). The quality of health care delivered to adults in the United States. New England Journal of Medicine, 348 , $2635-2645$.

McLellan, A. T., Arndt, I. O., Metzger, D. S., Woody, G. E., \& O’Brien, C. P. (1993). The effects of psychosocial services in substance abuse treatment. Journal of the American Medical Association, 269, 1953-1959.

McLellan, A. T., Kushner, H., Metzger, D., Peters, R., Smith, I., Grissom, G., et al. (1992). The fifth edition of the Addiction Severity Index. Journal of Substance Abuse Treatment, 9, 199-213.

McLellan, A. T., Luborsky, L., Woody, G. E., \& O’Brien, C. P. (1980). An improved diagnostic evaluation instrument for substance abuse patients. The Addiction Severity Index. Journal of Nervous and Mental Disease, $168,26-33$.

Mee-Lee, D., Shulman, G. D., Fishman, M., Gastfriend, D. R., \& Griffith, J. H. (Eds.). (2005). ASAM patient placement criteria for the treatment of substance-related disorders (2nd ed., revised). Chevy Chase, MD: American Society of Addiction Medicine.

Mersky, R. M., \& Dunn, D. J. (2002). Fundamentals of legal research (8th ed.). New York, NY: Foundation Press.

Morgan, T. J., Morgenstern, J., Blanchard, K. A., Labouvie, E., \& Bux, D. A. (2003). Health-related quality of life for adults participating in outpatient substance abuse treatment. American Journal on Addictions, $12,198-210$.

National Conference of State Legislatures. (2000a). State vote 2000: 2000 post-election party of state governors. National Conference of State Legislatures. [announcement posted on the World Wide Web]. 7-292005, from the World Wide Web: http://www.ncsl.org/programs legman/statevote/govParty_post2000.htm.

National Conference of State Legislatures. (2000b). State vote 2000: 2000 post-election party control of state legislatures. National Conference of State Legislatures. [announcement posted on the World Wide Web]. 7-29-2005, from the World Wide Web: http://www.ncsl.org/programs/ legman/statevote/legpartycontrol_post2000.htm. 
National Conference of State Legislatures. (2002a). State vote 2002: 2002 post-election party control of state legislatures. National Conference of State Legislatures. [announcement posted on the World Wide Web]. 7-29-2005, from the World Wide Web: http://www.ncsl.org/programs/ legman/statevote/legpartycontrol_post2002.htm.

National Conference of State Legislatures. (2002b). State vote 2002: 2002 post-election party of state governors. National Conference of State Legislatures. [announcement posted on the World Wide Web] 7-292005, from the World Wide Web: http://www.ncsl.org/programs/ legman/statevote/govParty_post2002.htm.

National Institute on Drug Abuse. (1999). Principles of drug addiction treatment: A research-based guide (NIH Publication Rep. No. 99-4180). Bethesda, MD: National Institute on Drug Abuse.

Nyamathi, A., Sands, H., Pattatucci-Aragon, A., Berg, J., \& Leake, B. (2004). Tuberculosis knowledge, perceived risk and risk behaviors among homeless adults: Effect of ethnicity and injection drug use. Journal of Community Health, 29, 483-497.

Orwin, R. G., Ellis, B., Williams, V., \& Maranda, M. (2000). Relationships between treatment components, client-level factors, and positive treatment outcomes. Journal of Psychopathology \& Behavioral Assessment, 22, 383-397.

Reif, S., Horgan, C. M., Ritter, G. A., \& Tompkins, C. P. (2004). The impact of employment counseling on substance user treatment participation and outcomes. Substance Use \& Misuse, 39, 2391-2424.

Robert Wood Johnson Foundation. (2006). Advancing recovery: State and provider partnerships for quality addiction care call for proposals. Princeton, NJ: Robert Wood Johnson Foundation.

Roman, P. M., Ducharme, L. J., \& Knudsen, H. K. (2006). Patterns of organization and management in private and public substance abuse treatment programs. Journal of Substance Abuse Treatment, 31, 235-243.

Rosenbloom, D. L., Garson, L. R., Shah, P., \& Ambrogi, R. (2006). Blueprint for the states: Policies to improve the ways states organize and deliver alcohol and drug prevention and treatment. Findings and recommendations of a national policy panel. Boston, MA: JoinTogether.

Siegal, H. A., Li, L., \& Rapp, R. C. (2002). Abstinence trajectories among treated crack cocaine users. Addictive Behaviors, 27, 437-449.

Thom, B., Brown, C., Drummond, C., Edwards, G., Mullan, M., \& Taylor, C. (1992). Engaging patients with alcohol problems in treatment: The first consultation. British Journal of Addiction, 87, 601-611.
U.S. Census Bureau. (2005). 1. Historical income tables-Households; Table H-8: Median household income by state: 1984-2004. [announcement posted on the World Wide Web] 1-26-2006, from the World Wide Web: http://www.census.gov/hhes/www/income/histinc/h08.html.

U.S. Department of Health and Human Services. (2005). National Survey of Substance Abuse Treatment Services, 2003 and 2004. (conducted by Mathematica Policy Research). [announcement posted on the World Wide Web] 1-16-2006, from the World Wide Web: http://webapp.icpsr. umich.edu/cocoon/SAMHDA-SERIES/00058.xml.

U.S. Department of Health and Human Services, Substance Abuse and Mental Health Services Administration, Office of Applied Studies (U.S. DHHS, SAMHSA, OAS). (2006a). National Survey of Substance Abuse Treatment Services (N-SSATS), 2004: [United States]. Synectics for Management Decisions [ICPSR04256-v2], 8-1-2006. Ann Arbor, MI: Inter-university Consortium for Political and Social Research

U.S. Department of Health and Human Services, Substance Abuse and Mental Health Services Administration, Office of Applied Studies (U.S. DHHS, SAMHSA, OAS). (2006b). Treatment Episode Data Set (TEDS), 2003. SAMHDA. [announcement posted on the World Wide Web], 2005, from the World Wide Web: http://webapp.icpsr.umich.edu/ cocoon/SAMHDA-STUDY/04257.xml.

U.S. Department of Health and Human Services, Substance Abuse and Mental Health Services Administration, Office of Applied Studies (U.S. DHHS, SAMHSA, OAS). (2006c). Treatment Episode Data Set (TEDS), 2004. SAMHDA. [announcement posted on the World Wide Web] 1-17-2007, from the World Wide Web: http://webapp.icpsr.umich. edu/cocoon/SAMHDA-STUDY/04431.xml.

Wells, R., Lemak, C. H., \& D'Aunno, T. A. (2005). Factors associated with interorganizational relationships among outpatient drug treatment organizations 1990-2000. Health Services Research, 40, 1356-1378.

Wells, R., Lemak, C. H., \& D'Aunno, T. A. (2006). Insights from a national survey into why substance abuse treatment units add prevention and outreach services. Substance Abuse Treatment, Prevention, and Policy, 1,21

Wheeler, J. R., Fadel, H., \& D'Aunno, T. A. (1992). Ownership and performance of outpatient substance abuse treatment centers. American Journal of Public Health, 82, 711-718.

Witkiewitz, K., \& Marlatt, G. A. (2004). Relapse prevention for alcohol and drug problems: That was Zen, this is Tao. The American Psychologist, $59,224-235$. 